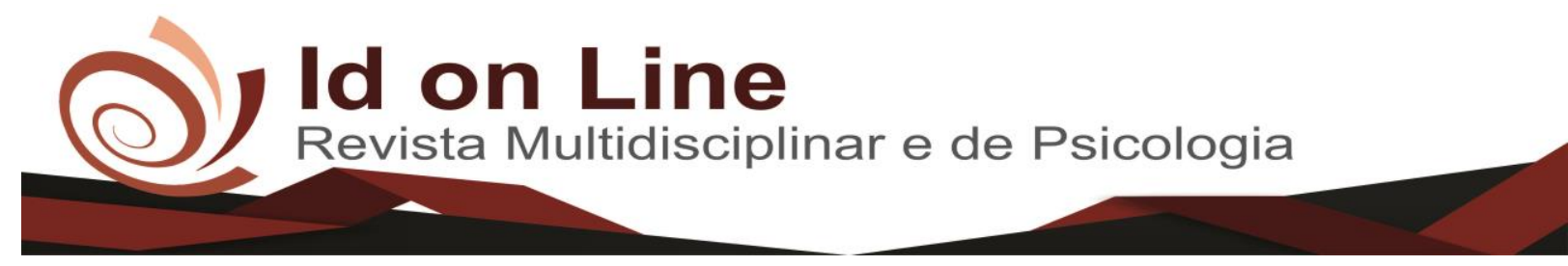

Artigo de Revisão

\title{
Os desafios éticos contemporâneos nas organizações públicas
}

\author{
Júlio Cezar Costa Ramos ${ }^{l}$; Allan Richards de Melo Nunes Morais ${ }^{2}$;Andrey Tavares da Silva ; \\ Fernanda Coelho de Figueiredo Soares Nascimento ${ }^{4}$; Tiago Gama do Nascimento ${ }^{5}$; \\ Francisco Ricardo Duarte 6
}

\begin{abstract}
Resumo: No Brasil a "crise ética" tem sido tema constante de debate, seja no ambiente acadêmico, nos programas de televisão, nas casas, no trabalho das pessoas, na rua e em todos os lugares. Sendo, na maioria das vezes, associada à atuação dos agentes públicos- Entre os principais focos das discussões, dessa forma segue-se a seguinte indagação: De que forma o curso de Especialização em Gestão Pública do Programa nacional de Formação em Administração Pública - PNAP vem a contribuir na formação técnica E comportamental dos agentes públicos? Que outras contribuições, pode fornecer ao Estado brasileiro? Vale destacar que a Gestão Pública não é formada apenas por agentes públicos. Empresas particulares e a sociedade civil também são de fundamental importância para a sua formação. Este artigo buscou analisar a importância de uma formação profissional de agentes públicos e da sociedade civil em Gestão Pública. Os resultados levaram a cerre que para se ter uma administração ética, lúcida e independente, deve haver uma profissionalização dos agentes políticos e uma formação mínima dos cidadãos, a fim de melhorarem as suas escolhas nas urnas e cobrarem as promessas feitas em campanha pelos agentes políticos eleitos.
\end{abstract}

Palavras-chaves: Ética; Gestão Pública; Formação de Gestores.

\section{Contemporary Ethical Challenges in Public Organizations}

\begin{abstract}
In Brazil, the "ethical crisis" has been a constant topic of debate, whether in the academic environment, in television programs, in homes, in the work of people, on the street, and everywhere. Being, most of the times, associated with the performance of public agents. Among the main focus of the discussions is the following question: How does the Specialization Course in Public Management of the National Public Administration Training Program (PNAP) contribute to the technical and behavioral training of public agents? What other contributions can you provide to the Brazilian state? It is worth mentioning that Public Management is not only composed of public agents. Private companies and civil society are also of fundamental importance for their training. This article sought to analyze the importance of professional training of public agents and civil society in Public Management. The results have led to the conclusion that in order to have an ethical, lucid and independent administration, there should be a professionalization of political agents and a minimum formation of citizens in order to improve their choices at the polls and to collect promises made in the campaign by political agents elected.
\end{abstract}

Keywords: Ethics; Public administration; Training of Managers.

\footnotetext{
${ }^{1}$ Universidade Federal Vale do São Francisco - UNIVASF. Autor Correspondente. Contato: juliooccr@gmail.com;

${ }^{2}$ Especialização em Ensino Superior, Contemporaneidade e Novas Tecnologias pela Universidade Federal do Vale do São Francisco. Mestrado em Administração Pública pela UNIVASF;

${ }^{3}$ Graduação em Análise e Desenvolvimento de Sistemas pela Universidade Norte do Paraná, Brasil. Coordenador Técnico da

${ }^{4}$ Universidade Federal Vale do São Francisco - UNIVASF;

${ }^{5}$ Graduação em Engenharia Civil pela Universidade Federal do Vale do São Francisco, Especialização em Estruturas de Concreto e Fundações pela Universidade Cidade de São Paulo.

Rede Metropolitana do Vale do São Francisco , Brasil;

${ }^{6}$ Universidade Federal Vale do São Francisco - UNIVASF.
} 


\section{Introdução}

A familiaridade com a palavra ética vem crescendo no Brasil a cada dia, bem como a utilização de seus significados. Antes entendida como parte do estudo da Filosofia responsável pela explicação das atitudes humanas atreladas ao seu contexto social, a ética é tida como a solução para quase todas as crises da humanidade.

O estudo sobre a ética veio a ganhar espaço na Grécia antiga, a partir do século IV a.C. com a racionalização das questões éticas proposta pelos filósofos Sócrates, Platão e Aristóteles. Entretanto, tem-se notícias de utilização de preceitos éticos desde que o homem passou a viver em sociedade.

O objetivo desse artigo foi analisar o quanto a qualificação dos servidores públicos brasileiros e da sociedade civil pode resultar na mudança de postura desses servidores e incorrer em atitudes éticas e responsáveis na execução dos seus trabalhos diários, introduzindo assim, constantes melhorias na Administração Pública. Para dar fundamento ao objetivo proposto, utilizaremos o curso de Especialização em Gestão Pública do PNAP como objeto de estudo. Entre os tantos outros, neste artigo utilizaremos o seguinte conceito para ética: "É o estudo do comportamento humano, investigação sobre o que é bom e o que é mau, e sobre o modo de se estabelecerem, histórica e teoricamente, normas válidas para todos" (ASSMANN, 2012, p. 85).

Para Administração Pública, utilizaremos o conceito de Meirelles (2004 apud JUNQUILHO, 2012): "a totalidade de serviços e entidades ligados ao Estado", sendo caracterizada como todas as programações, ações, gastos, e outras atividades praticadas por agentes públicos, com o objetivo de atender às demandas da sociedade.

A "máquina pública” brasileira conta com mais de 10 milhões de servidores públicos, se considerados todos os entes da federação, e envolve as mais variadas atividades fundamentais para o funcionamento do Estado brasileiro. Para a gestão de toda essa gente e todo o dinheiro público envolvido, não basta a "boa vontade" de agentes políticos e administrativos, nem a definição dos interesses do órgão ou do grupo político no qual está inserido. Todo agente público, independentemente de ser político ou administrativo, deve ser qualificado. Essa qualificação vai desde uma formação técnica até a comportamental.

Pelo exposto nos indagamos, de que forma o curso de Especialização em Gestão Pública do PNAP vem a contribuir na formação técnica E comportamental dos agentes públicos?. Que outras contribuições, pode fornecer ao Estado brasileiro? 


\section{Material e Método}

O método utilizado para a elaboração desse artigo foi Pesquisa Bibliográfica, tendo como base as bibliografias adotadas nas matérias do curso de Especialização em Gestão Pública do PNAP, ofertado pela Univasf. Foi feita também uma contextualização dos temas abordados com a ética, relacionando cada matéria aos conceitos e aplicações dela, aos novos desafios da Administração Pública brasileira.

$\mathrm{O}$ artigo está dividido em duas partes, além da introdução e considerações finais. $\mathrm{Na}$ próxima seção, será feita uma apresentação geral do curso de Especialização em Gestão Pública do PNAP no contexto do tema deste artigo. Na quarta seção, faremos uma revisão bibliográfica nos textos base utilizados nas disciplinas do curso e apontaremos a relação de cada matéria com a ética na Administração Pública.

\section{O Curso de Gestão Pública}

O Programa Nacional de Formação em Administração Pública - PNAP nasceu da preocupação governamental com a gestão pública, principalmente, após a promulgação da Constituição Federal de 1988, quando os municípios e o Distrito Federal passaram a ter autonomia política, administrativa e financeira, sendo inseridos no rol dos entes federativos. Sua idealização se deu com a percepção de que os municípios menores e mais afastados dos grandes centros não estavam evoluindo na gestão dos seus recursos, nem se enquadrando em qualquer padrão de qualidade no atendimento às demandas da sociedade, necessitando de capacitação específica e direcionada para os problemas locais.

Os cursos de pós-graduação do programa têm como objetivos, de acordo com o seu projeto básico:

\footnotetext{
Capacitar quadros de gestores para atuarem na administração de macro (governo) e micro (unidades organizacionais) sistemas públicos.

$>\quad$ Capacitar profissionais com formação adequada a intervirem na realidade social, política e econômica.

Contribuir para a melhoria da gestão das atividades desempenhadas pelo Estado brasileiro, nos âmbitos federal, estadual e municipal.

$>\quad$ Contribuir para que o gestor público desenvolva visão estratégica dos negócios públicos, a partir do estudo sistemático e aprofundado da realidade administrativa do governo ou de suas unidades produtivas (BRASIL, 2012).
} 
O curso de Especialização em Gestão Pública do PNAP, ofertado pela Univasf conta 510 (quinhentas e dez) horas, divididas em uma grade curricular com 16 disciplinas: Introdução a Modalidade Educação a Distância; Estado, Governo e Mercado; O Público e o Privado na Gestão Pública; Desenvolvimento e Mudanças no Estado Brasileiro; Políticas Públicas; O Estado e os Problemas Contemporâneos; Indicadores Socioeconômicos na Gestão Pública; Comportamento Organizacional; Metodologia Científica; Cultura e Mudança Organizacional; Planejamento Estratégico Governamental; Redes Públicas de Cooperação em Ambientes Federativos; Gestão Operacional; Gestão Logística; Plano Plurianual e Orçamento Público; e Monografia.

\section{Contribuições da literatura}

Analisemos então as contribuições das disciplinas do curso de Especialização em Gestão Pública do PNAP, na formação profissional dos discentes, com o foco na ética na Administração Pública.

\section{Introdução a Modalidade Educação a Distância}

A disciplina tem como objetivo preparar os discentes para a modalidade de educação a distância - EAD. O seu foco é trazer os novos modelos de aprendizagem que proporcionados por esta modalidade de ensino, principalmente, no compartilhamento da responsabilidade do aprendizado do professor com o aluno, ficando aquele, com a responsabilidade de atuar mais como um facilitador de aprendizagem do que como o dono do conhecimento a ser transferido para o estudante. Outros atores também são de fundamental importância na EAD, tais como: os tutores, o coordenador do curso, os técnicos responsáveis pela plataforma virtual, e os agentes administrativos lotados nos polos presenciais de ensino.

Em um país com dimensões continentais como Brasil, são grandes as dificuldades para levar educação de qualidade, de forma presencial, para as áreas mais afastadas. A educação a distância tem crescido bastante, graças ao desenvolvimento das tecnologias de informação, comunicação e ao alcance da mesma, vai além da questão territorial. Pelo fato de o discente poder escolher o melhor momento para estudar, através de plataformas virtuais e material didático disponibilizado pelo professor (livros, e-books, vídeos, apostilas), a EAD consegue 
atender às demandas de aprendizado das pessoas que não tinham a menor condição de se deslocar para uma sala de aula 5 dias por semana. Caminheiros, jogadores de futebol, vendedores externos (que trabalham viajando), mães que não têm com quem deixar os filhos para ir a uma faculdade, pessoas com incapacidade ou dificuldade de locomoção, entre outras, passaram a ter a oportunidade de frequentar cursos de qualidade, sem saírem de suas casas.

Entre os principais benefícios da modalidade de Educação a Distância, considerando a gestão dos recursos públicos em prol da coletividade, podemos citar: a universalização do conhecimento; o baixo custo, se comparado ao custo da educação presencial; o aumento da autoestima dos discentes, que têm a responsabilidade de serem os principais atores no processo de aprendizagem; a otimização do tempo e possibilidade de acesso ao material de estudo em horários não convencionais.

Para Daumal (2007, p.66): “o sucesso da aprendizagem é derivado do interesse e da manutenção deste ao longo do curso". O autor reforça ainda a responsabilidade do estudante da modalidade à distância, que deve ser estendida a sua atuação enquanto agente público ou fiscal a atuação deste.

\section{Estado, Governo e Mercado}

A disciplina tem como objetivo principal trazer os principais conceitos referentes a Estado, Governo e Mercado; suas relações, variações no decorrer da história; e as principais utilidades desses conceitos no dia a dia dos agentes públicos.

Um dos principais preceitos éticos é “agir sempre em busca de um bem comum”. Mas, qual seria esse bem? Representantes do Estado têm que tomar diariamente decisões que podem trazer o bem, o mal, ou os dois ao mesmo tempo para sociedade. Para que essas decisões sejam tomadas da forma mais coerente possível, esses servidores públicos têm que ter a total conhecimento da sua função como representante do povo e das consequências dessas decisões.

Outras discussões que também envolvem a disciplina, são referentes ao "tamanho do Estado" e "qual o grau de liberdade que o Mercado deve possuir". Esses questionamentos sempre serão atuais em todos os Governos. De acordo com Coelho (2012, p. 7): "Por mais que se tenha buscado, e ainda se continue buscando, encontrar o ponto de equilíbrio entre a intervenção estatal e a liberdade de mercado, esse equilíbrio não poderá ser mais que temporário". 
Nesse contexto, deve-se buscar incessantemente esse equilíbrio, seja através de intervenção estatal em atividades privadas, incentivos governamentais em áreas estratégicas do Mercado, ou até mesmo saindo de cena e deixando o Mercado se reorganizar em determinados momentos.

\section{O Público e o Privado na Gestão Pública}

O Brasil vem de uma cultura Patrimonialista desde o seu descobrimento. Escândalos de corrupção envolvendo agentes públicos e empresas privadas, a exemplo do Departamento de Propina operado pela empresa Odebrecht, no qual se contabilizava todos pagamentos irregulares em troca de benefícios em processos públicos; só reforçam a ideia de que toda a cultura política do país é propensa a essa "confusão de distinção" entre o que é público ou privado.

Empresas e particulares patrocinam os políticos, que indicam os seus aliados para os cargos públicos, estes tomam as principais decisões do país em favor dos grupos aliados, prejudicando a maioria da sociedade. Nesse jogo, todos saímos perdendo. A disciplina tem como principais tópicos: a dicotomia entre o público e ou privado; prerrogativas do público sobre o privado e a relação entre o Estado e os servidores públicos; e os princípios da Administração Públicas e suas relações com o setor privado.

\footnotetext{
Nesta disciplina, as fronteiras que demarcam os espaços da esfera pública e da esfera privada, dos interesses privados e dos interesses coletivos, dos direitos do cidadão e dos poderes e deveres do Estado, foram tratadas a partir das contribuições da Filosofia e do Direito - o que é inescapável -, mas sempre de forma contextualizada e por meio de exemplos representativos de situações do dia a dia do gestor público (COELHO, 2009 , p. 8).
}

No decorrer dos estudos, os alunos tiveram acesso, além dos conceitos básicos da disciplina, a conteúdos norteadores da boa atuação quando investidos em cargos públicos ou no exercício cidadania.

\section{Desenvolvimento e Mudanças no Estado Brasileiro}

A disciplina tem como objetivo "analisar o processo de construção da estrutura de Estado no Brasil, da Proclamação da República até os dias atuais" (LEITE JÚNIOR, 2012, p. 7). 
A partir dessa análise, o aluno do curso de Especialização em Gestão Pública pode entender um pouco do contexto atual da Administração Pública brasileira e comparar com fases anteriores. Esse conhecimento enriquecerá a base ética do aluno e o ajudará a não incorrer em erros praticados reiteradamente no âmbito das organizações públicas.

Para a melhor compreensão do assunto, a disciplina foi organizada em três etapas, de acordo com a ordem cronológica e o momento histórico da sociedade brasileira: 1) da República Velha ao Regime Militar; 2) o Regime Militar; e 3) da Nova República aos dias atuais.

Após o estudo da disciplina, podemos chegar à conclusão de que avançamos muito em pouco mais de 200 anos de independência. Entretanto, fica evidente que algumas práticas nocivas à Administração Pública ainda insistem em existir, cabendo aos Gestores Públicos a elaboração de normas capazes de eliminar as práticas irregulares e punir os agentes envolvidos.

\section{Políticas Públicas}

Ficaria impossível tratar de Administração Pública e ética sem tratarmos da elaboração de políticas públicas. É através das políticas públicas que os agentes guiam as ações dos seus Governos. O objetivo geral da disciplina Políticas Públicas é:

Levar o estudante a perceber as duas faces da Política Pública: a de planejamento aparentemente racional e neutro realizado pelo Estado (policy) e a de resultante de ações dos atores políticos visando à defesa dos seus interesses e valores (politics) (RUA, 2012, p. 7).

A partir do objetivo geral, a disciplina tratou dos conceitos básicos de política pública, seus ciclos e da sua implementação. Outro ensinamento importante foi de que "bem comum" muitas vezes vai ser diferente do "bem de todos". Isso porque as prerrogativas dos agentes públicos trazem a possibilidade de eles agirem em prol do bem comum, mesmo que tire algum tipo de direito de qualquer membro da sociedade. Como exemplo disso, temos a política de segurança pública, onde pessoas que cometem crimes são privadas de sua liberdade.

No contexto da base ética inerente aos servidores públicos, podemos tirar o aprendizado da disciplina de que a elaboração, implementação e acompanhamento de uma política pública envolve diversos fatores e agentes. Devendo, cada ator investido no serviço público, seja político ou administrativo, ter a consciência de que ele é o maior responsável pela busca do bem comum, através da implementação das políticas públicas. 


\section{O Estado e os problemas contemporâneos}

Pobreza, desigualdade, exclusão e cidadania, são alguns dos temas que a sociedade brasileira sempre foi acostumada a debater e cobrar políticas públicas no intuito de corrigir distorções e melhorar a qualidade de vida da das pessoas.

A disciplina de "O Estado e seus Problemas Contemporâneos" busca trazer ao aluno as dimensões históricas dos estudos e políticas sociais do Brasil. Santos (2009, p. 7) destaca que são vários os problemas do Estado brasileiro, entre eles, a indecisão sobre qual o papel que o Estado pode e deve desempenhar na promoção de soluções para atender às demandas da sociedade contemporânea.

Para que os agentes públicos possam tomar decisões com o alcance necessário, a fim de acabar com determinados problemas da sociedade, faz-se necessário o conhecimento aprofundado sobre a nação. E para que eles possam traçar as diretrizes das políticas públicas com eficiência, têm que estar cientes do contexto econômico, cultural e social dos atores envolvidos.

\section{Indicadores Socioeconômicos na Gestão Pública}

Uma das principais características dos governos patrimonialistas é a personificação de agentes políticos, administrativos, representantes da sociedade que possam trazer mais votos para o agente político e parcelas da população que possam trazer mais benefícios para os grupos dominadores. A partir dessa personificação, as políticas públicas são direcionadas, ferindo todos os princípios da Administração Pública e fazendo da máquina pública uma grande propriedade particular.

A partir do momento em que são traçados indicadores socioeconômicos na gestão pública, o Estado passa a priorizar as áreas com maior necessidade intervenção através de políticas públicas e dá um salto da Administração Patrimonialista para a Gerencial. Como principais tópicos estudados tivemos os conceitos básicos sobre indicadores sociais; as principais pesquisas, fontes de dados e indicadores; e a introdução às fontes de dados e indicadores econômicos. Jannuzi (2012) afirma que:

Qualquer profissional, técnico ou gestor que atue no setor público ou em áreas próximas, que queira compreender melhor o debate atual sobre desemprego, pobreza, desenvolvimento econômico local, impactos ambientais ou que precise formular e implementar programas, projetos e ações nessas áreas necessita entender mais 
profundamente o que são os Indicadores Socioeconômicos, para que servem, como são construídos e como podem ser usados na elaboração de diagnósticos e em outras atividades do Planejamento Governamental e da Gestão Pública (JANNUZI, 2012, p. 7).

Portanto, podemos chegar à conclusão de que uma administração ética e responsável começa com a elaboração de indicadores socioeconômicos capazes de dar subsídios para os agentes públicos traçarem as prioridades da sociedade e acompanhar o desenvolvimento desses indicadores.

\section{Comportamento Organizacional}

Um país com mais de 200 milhões de habitantes e com dimensões continentais como o Brasil, exige uma grande quantidade servidores públicos para gerir e organizar a Administração Pública. E para gerenciar esses servidores, se farão necessários gestores capacitados para levar as organizações obter o melhor desempenho e manter os colaboradores sempre motivados. Assim, o Comportamento Organizacional está ligado à maneira na qual servidores e organizações se portam no desempenho de suas atividades.

A disciplina tem como propósito discutir o Comportamento Organizacional com ênfase na Administração Pública (BERGUE, 2012, p.7). Os principais tópicos abordados são: a motivação no setor público; processos organizacionais; e estrutura e comportamento em organizações públicas.

O conhecimento sobre a gestão do comportamento organizacional se faz necessário para que o gestor possa inserir no contexto organizacional as mudanças necessárias, a fim de suprir as necessidades das organizações públicas e da sociedade civil.

\section{Metodologia Científica}

A disciplina discute a importância da implantação de uma metodologia em pesquisa em Administração Pública. Espera-se que muitos tenham ciência dos avanços que devemos buscar na Administração Pública, principalmente na geração de conhecimento, enquadrando os resultados das pesquisas no campo do Conhecimento Científico, de acordo com parâmetros nacionais e internacionais. 
Para quem pretende realizar pesquisas, desenvolver atividades específicas de gestão em organizações públicas, participar da elaboração, do planejamento, da coordenação e do controle de políticas públicas, o conhecimento sobre métodos de pesquisa contribui de maneira significativa na análise, na avaliação e na aplicação dos resultados, visando a melhoria da sociedade. Zannela (2012) destaca que:

\begin{abstract}
A função do agente público é cercada de afazeres que vão além de uma rotina diária. Este agente tem que estar sempre prestando contas para a sociedade e propondo melhorias para a gestão pública, sempre de forma escrita, tal qual a Monografia. À sociedade civil cabe a fiscalização sobre a prestação do serviço público, através dos documentos gerados pelos agentes públicos, e a colaboração com o poder público para desenvolvimento social (ZANNELLA, 2012, p. 10).
\end{abstract}

A ausência de uma metodologia de pesquisa e a falta de parâmetros na elaboração do conhecimento, faz do agente público um refém de sua própria consciência, ou das pessoas que o influenciam, indo contra a busca do bem comum.

Portanto, a utilização de uma metodologia de pesquisa não se dá apenas no contex to da pesquisa científica, é de fundamental importância para que o administrador público possa produzir materiais que propiciem o melhoramento da atividade Estatal.

\title{
Cultura e mudança organizacional
}

Historicamente, a Administração Pública brasileira passou por diversas fases, tendo vivido diversos momentos de turbulências e mudanças. Isso se dá devido as alterações de comportamento da sociedade e a necessidade de acompanhar "o mundo" no processo de globalização e modernização proporcionado, principalmente, pelo avanço tecnológico. Nesse sentido, Bergue (2012, p.9) destaca que falar de cultura e mudança organizacional, será sempre uma constante em qualquer organização, pois as organizações estão em constante mutação.

Com base no conteúdo disposto no material didático (livro, apostila e vídeo aulas) da disciplina, podemos chegar à conclusão de que os gestores públicos precisam estar sempre preparados para implantar essas mudanças, os demais servidores para acompanhar e a sociedade civil para cobrar desses servidores o melhor desempenho no uso de suas atribuições. Assim, fica evidenciada a importância do estudo da cultura e mudança organizacional. 


\section{Planejamento Estratégico Governamental}

A disciplina traz a discussão sobre a necessidade de desvinculação do "Estado herdado" e uma constante busca por um "Estado necessário". Por "Estado herdado" podemos entender a forma de governar baseada em experiências anteriores, adaptada às novas gestões. Já por "Estado necessário" podemos entender um Estado programado para atender às necessidades de sua população, um Estado voltado par a o desenvolvimento, sem deixar de lado os mais necessitados.

O Planejamento Estratégico Governamental - PEG é uma ferramenta necessária para que tenhamos uma certa constância nas organizações pública e para evitar que agentes públicos “mal-intencionados “ coloquem os seus objetivos à frente dos objetivos organizacionais.

No Brasil, o PEG passou a ser implantado a partir da reforma da Administração Pública Gerencial dos anos 90. Como citado na introdução deste artigo, nem todos os entes governamentais acompanharam a reforma da Administração Gerencial, sendo a disciplina de Planejamento Estratégico Governamental uma disseminadora de conhecimento e propulsora da implantação do PEG em todos os entes da federação.

\section{Redes Públicas de Cooperação em Ambientes Federativos}

A Constituição Federal de 1988 concedeu diversos poderes e competências a estados e municípios que antes eram centralizados. Se por lado, facilitou o trato dos problemas de uma forma regionalizada, onde eles realmente acontecem, por outro, gerou diversos problemas como a falta de capacitação desses entes estatais e algum tipo de conflito de competências entre eles.

Para Rede, utilizaremos o conceito que Migueleto (2001 apud MALMEGRIN, 2010) traz:

\footnotetext{
A rede é um arranjo organizacional (sistema organizacional) formado por um grupo de atores, que se articulam - ou são articulados por uma autoridade - com a finalidade de realizar objetivos complexos, e inalcançáveis de forma isolada. A rede é caracterizada pela condição de autonomia das organizações e pelas relações de interdependência que estabelecem entre si. É um espaço no qual se produz uma visão compartilhada da realidade, se articulam diferentes tipos de recursos e se conduzem ações de forma cooperada. O poder é fragmentado e o conflito é inexorável, por isso se necessita de uma coordenação orientada ao fortalecimento dos vínculos de confiança e ao impedimento da dominação (MIGUELETTO, 2001 apud MALMEGRIN, 2010, p. 16).
} 
Vale lembrar que os entes federativos vivem em constantes conflitos éticos proporcionados pelos ambientes de Competição e Cooperação entre eles. Assim, itens como, verbas do executivo, emendas parlamentares, a instalação de grandes empresas e órgãos públicos, são disputas constantes entre eles. Em alguns casos, observa-se a busca pela cooperação em áreas como saúde e educação.

A disciplina de Redes Públicas de Cooperação em Ambientes Federativos traz essa Rede como sinônimo de desenvolvimento federativo, no qual, a Cooperação pode ultrapassar os métodos convencionais, proporcionando economia e efetividade do poder público como um todo.

\section{Gestão Operacional}

O objetivo geral da disciplina Gestão Operacional é discutir o conjunto de ações que devem ser planejadas e executadas para a melhoria contínua da prestação de serviços públicos.

De acordo com Malmegrin (2012):

Gestão Operacional está configurada como um espaço integrador das competências que um gestor público deve possuir para exercer uma efetiva gestão da prestação de serviços públicos, por um órgão do Estado ou mesmo por uma entidade não estatal (MALMEGRIN, 2012, p. 12).

Nesta concepção, todo gestor público deve buscar incansavelmente melhorar o processo de gestão e otimizar o serviço. No desenrolar da disciplina foram tratados os seguintes tópicos: os conceitos básicos de gestão operacional; os ciclos de gestão; as gestões operacionais críticas; e o controle operacional e os sistemas de gestão. Tais conhecimentos possibilitaram o aprimoramento da capacidade do gestor na transformação da organização.

\section{Gestão Logística}

Muitas vezes entendida como a atividade de entrega de algum produto, a Gestão Logística representa muito mais do que isso. Ela é a harmonia no que se refere a gestão. Costa (2010) define a logística como:

A colocação do produto certo, na quantidade certa, no lugar certo, com o prazo certo, na qualidade certa, com a documentação certa, ao custo certo, produzindo ao menor custo, da melhor forma, deslocando mais rapidamente, agregando valor ao produto e 
dando resultados positivos aos acionistas e clientes. Tudo isso respeitando a integridade humana de empregados, fornecedores e clientes, e a preservação do meio ambiente. (DA COSTA, 2010, p 17).

A disciplina tem como objetivo geral oferecer ao estudante uma estratégica para a redução de custos, a otimização de processos e a administração de materiais, de forma a atender diretamente essas áreas no que diz respeito ao gerenciamento da cadeia de atendimento.

Para exemplificarmos a importância da Gestão Logística, suponhamos a falta de materiais de higiene e limpeza em um hospital ou posto de saúde. Mesmo sem ser de uso direto na área fim, esta falta de materiais inviabilizaria o atendimento médico e ambulatorial aos pacientes.

Em um ambiente macro, enquanto gestores públicos, temos consciência de que uma má gestão logística causa danos para a sociedade ao longo do tempo. Cabe aos gestores públicos a missão de proporcionar uma melhoria nessa área tão importante para o desenvolvimento nacional.

\section{Plano Plurianual e Orçamento Público}

Os déficits orçamentários sucessivos são a prova do mal-uso do dinheiro público e do descontrole governamental brasileiro. Isso não ocorre apenas no governo federal, estados e municípios também apresentam diversas dificuldades na gestão do seu orçamento.

Santos (2010, p. 9) destaca que "é importante reconhecermos que o orçamento público pode ser instrumento de boa ou de má gestão pública, dependendo da qualidade do planejamento que ele reflita".

A disciplina de Plano Plurianual e Orçamento Público traz para o aluno uma base de como o Orçamento é planejado, executado e controlado. Sem essa base, acreditamos que nenhum agente público deveria ter o poder de tomar qualquer decisão que envolvesse a gestão dos recursos públicos.

\section{Monografia}

Essa componente curricular tem o intuito de orientar o discente para a elaboração do trabalho final do curso e verificar o andamento do mesmo. 
O curso tem como obrigatoriedade para a obtenção do Certificado de Especialista em Gestão Pública, a apresentação de um artigo científico (aceito em revista com corpo editorial ou trabalho completo publicado em anais de evento científico) ou monografia, que revele o domínio a respeito de um tema relacionado aos assuntos tratados no seu decorrer.

Nessa fase, o discente apresenta o produto final de sua pesquisa, com base no conhecimento adquirido no decorrer do curso.

\section{Considerações Finais}

Podemos visualizar no decorrer desse artigo, que a formação em Administração/Gestão Pública, é de grande relevância para a melhoria da qualidade do serviço público prestado a sociedade. Considerando que as disciplinas que compõem o curso de Especialização em Gestão Pública do PNAP não são exaustivas, devem ser amparadas e complementadas por diversos outros ramos de conhecimento. Esses ensinamentos, muitas vezes, são interligadas e acabam por depender uns dos outros.

Nós brasileiros, estamos sedentos por uma Administração Pública de qualidade, onde os gastos estatais sejam equilibrados e voltados para o bem da sociedade. Devemos ter a consciência de que a busca pelo desenvolvimento não deve parar, não podemos esquecer também das dívidas sociais históricas com os menos favorecidos.

A capacitação dos servidores públicos ajuda a minimizar a complexidade da gestão de um país de grande extensão territorial como o Brasil, cuja desigualdade social, diversidade de clima, cultura e economia entre as suas diversas regiões acaba gerando mais demandas para o Estado. É necessário também, inovar em maneiras de combater a corrupção em todas as esferas estatais e proteger a máquina pública de agentes públicos desqualificados.

Não podemos deixar de destacar, a importância do engajamento de toda a sociedade na gestão da coisa pública. Os reais detentores do poder têm papel fundamental na hora de cobrar dos governantes eleitos as melhorias na gestão dos recursos e aprimoramento das leis, a fim de suprir todas as deficiências de gestão herdadas de governos passados.

Considera-se que para se ter uma administração ética, lúcida e independente, deve haver uma profissionalização dos agentes políticos e uma formação mínima dos cidadãos, a fim de melhorarem as suas escolhas nas urnas e cobrarem as promessas feitas em campanha pelos agentes políticos eleitos. 


\section{Novos desafios éticos da Administração Pública}

A transformação acelerada do mundo e as "novas" necessidades humanas trouxeram sérias modificações nas relações sociais e na relação dos usuários de serviços públicos com a Administração Pública que, em alguns casos, não tem conseguido acompanhar todo esse desenvolvimento.

Aos gestores públicos cabe o alinhamento das funções da Administração Pública com os avanços tecnológicos e de mentalidade da sociedade, sem ferir à legislação vigente e a ética necessária para perpetuação da espécie humana.

Alguns temas como a Bioética, a proteção ao meio ambiente, a proteção do emprego, o enfoque sistêmico das organizações, os novos arranjos institucionais, a cooperação internacional, as novas configurações das famílias, entre outros, exigem dos tomadores de decisões de dos planejadores do futuro da Administração Pública uma formação sólida, consciente e inovadora para desenvolver políticas públicas capazes de abraçar a todas as causas da melhor forma possível.

\section{Referências}

ASSMANN, Selvino José. Filosofia e Ética. Florianópolis: Departamento de Ciências da Administração/UFSC, 2012.

BERGUE, Sandro Trescastro. Comportamento Organizacional. Florianópolis: Ciências da Administração/UFSC, 2012.

. Cultura e mudança organizacional. Florianópolis: Departamento de Ciências da Administração/UFSC, 2010.

BRASIL. Ministério da Educação. Coordenação de Aperfeiçoamento de Pessoal de Nível Superior. Diretoria de Educação a Distância. Programa Nacional de Formação em Administração Pública. Projeto Pedagógico do Curso de Especialização em Gestão Pública Modalidade a Distância. Brasília, 2012.

COELHO, Ricardo Corrêa. A dicotomia Público/Privado. O público e o privado na gestão pública. Florianópolis: Departamento de Ciências da Administração/UFSC, 2009.

/ UFSC, 2012.

Estado, governo e mercado. Florianópolis : Departamento de Ciências da Administração

COSTA, Celso da. 2010. Prefácio. In ROSA, Rodrigo de Alvarenga. Gestão Logística. Florianópolis: Departamento de Ciências da Administração/UFSC, 2010.

DAGNINO, Renato Peixoto. Planejamento Estratégico Governamental. Florianópolis: Departamento de Ciências da Administração/UFSC, 2012. 
DAUMAL, Marcos Baptista Lopez. Introdução à Educação a Distância. Florianópolis: Departamento de Ciências da Administração/UFSC, 2007.

JANNUZZI, Paulo de Martino. Indicadores socioeconômicos na gestão pública. Florianópolis: Departamento de Ciências da Administração/UFSC, 2012.

JUNQUILHO, Paulo de Martinho. Teorias da Administração Pública. Florianópolis: Departamento de Ciências da Administração/URFC, 2012.

LEITE JÚNIOR, Alcides Domingues. Desenvolvimento e mudanças no estado brasileiro. Florianópolis: Departamento de Ciências da Administração/UFSC, 2009.

MALMEGRIN, Maria Leonídia. Redes Públicas de Cooperação em Ambientes Federativos. Florianópolis: Ciências da Administração/UFSC, 2010.

Gestão Operacional. Florianópolis: Ciências da Administração/UFSC, 2012.

ROSA, Rodrigo de Alvarenga. Gestão logística. Florianópolis: Departamento de Ciências da Administração/UFSC, 2010.

RUA, Maria das Graças. Políticas Públicas. Florianópolis: Departamento de Ciências da Administração/UFSC, 2012.

SANTOS, Maria Paula Gomes dos. O Estado e os problemas contemporâneos. Florianópolis: Departamento de Ciências da Administração/UFSC, 2009.

SANTOS, Rita de Cássia. Plano plurianual e orçamento público. Florianópolis: Departamento de Ciências da Administração/UFSC, 2010.

ZANELLA, Liane Carly Hermes. Metodologia de estudo e de pesquisa em administração. Florianópolis: Departamento de Ciências da Administração / UFSC, 2012.

\section{Como citar este artigo (Formato ABNT):}

RAMOS, Júlio Cezar Costa; MORAIS, Allan Richards de Melo Nunes; SILVA, Andrey Tavares da; NASCIMENTO, Fernanda Coelho de Figueiredo Soares; NASCIMENTO, Tiago Gama do; DUARTE, Francisco Ricardo. Os desafios éticos contemporâneos nas organizações públicas. Id on Line Rev.Mult. Psic., 2019, vol.13, n.43, p. 1056-1071. ISSN: 1981-1179.

Recebido: $11 / 12 / 2018$

Aceito: $12 / 12 / 2018$ 